\title{
RESEÑAS
}





\section{CAMINOS DE JUSTICIA. AUTOGOBIERNO RARÁMURI, RETOS Y REALIDADES. \\ VALDIVIA RAMÍREZ, FÁTIMA DEL ROCÍO, D’Madrid Editores, México, 2015}

Martha Paola FERNÁNDEZ LOZANO

Pensar en la protección de los derechos de las personas, pueblos y comunidades indígenas desde el marco de los derechos humanos implica reflexionarlos como derechos individuales y colectivos, y no sólo desde el carácter individual y universal de la teoría occidental de los derechos humanos. La cultura, la libre determinación y el territorio, son algunos de esos derechos colectivos que cobran un énfasis mayúsculo cuando de pueblos indígenas hablamos. La garantía de los derechos indígenas dentro del Estado mexicano implica una discursiva de reconocimiento cultural de su existencia, y un reconocimiento como sujetos de derecho, como agentes políticos en los espacios del Estado que se van construyendo desde sus propias complejidades y contradicciones. En otras palabras, para una auténtica garantía de los derechos indígenas es fundamental darle la connotación política al reconocimiento cultural de los pueblos.

Desde la propia reflexión, experiencia y análisis de los indígenas rarámuris, Fátima del Rocío Valdivia Ramírez coloca Caminos de Justicia. Autogobierno Rarámuri, retos y realidades como un libro que se narra desde la propia historia del pueblo. Resultado de un taller de análisis sobre la Ley de Derechos de los Pueblos Indígenas del Estado de Chihuahua, realizado por el Centro de Capacitación y Defensa de los Derechos Humanos e Indígenas A.C., la Pastoral Indígena, los coordinadores del Proceso de Fe Compartida y el Comité de Derechos Humanos P. Francisco Chávez con autoridades rarámuris de la zona, surge este texto que como bien subraya en la introducción tiene por objeto el de esbozar el significado comunitario que aún guarda el sistema de autoridades propio ${ }^{2}$ y los retos a los que se enfrentan.

La autora coloca el autogobierno indígena en el centro del desarrollo del libro, determina su campo de análisis a los centros de reunión Norogachi, Rocheachy y Samachike de la Sierra Alta Tarahumara, y lo estructura en cuatro apartados que van explicando la genealogía de organización político-jurídica de los indígenas, que dista de la concepción tradicional que tenemos del derecho.

En pluralidad jurídica, una consecuencia de la diversidad cultural, plantea el fundamento socio-jurídico del derecho al autogobierno desde el debate que se genera con el reconoci-

\footnotetext{
${ }^{1}$ Estudiante de la Licenciatura en Derecho de la Universidad de Guanajuato, integrante del Programa Universitario de Investigaciones Jurídicas de la División de Derecho, Política y Gobierno de la Universidad de Guanajuato. Correo electrónico: fdzlmp@gmail.com

${ }^{2}$ VALDIVIA RAMÍREZ, Fátima del Rocío, Caminos de Justicia. Autogobierno Rarámuri. Retos y realidades, D’Madrid Editores, México, 2015, p. 12.
} 
miento multicultural, el derecho a las diferencias y la pluralidad jurídica. Este debate que, grosso modo y siguiendo la lectura, oscila en preguntarnos: ¿dónde se encuentran los derechos indígenas?, ¿basta con el reconocimiento legal?, ¿en qué consiste este derecho a las diferencias o a ser diferente?, ¿cuál ha sido el costo del multiculturalismo y cómo hemos de llevar al terreno de los hechos de la pluralidad jurídica?

El multiculturalismo, surge en los 6o's-70's, relativamente a la par de los movimientos autonómicos en Latinoamérica (ya no se sabe si como solución alternativa o como contramovimiento), ${ }^{3}$ y ha dado la apariencia -como lo enuncia Valdivia Ramírez- de ser una política apacible con las diferencias y suficiente para lograr el estado democrático de derecho, pero que se ha convertido en una herramienta política que amuralla la autonomía de las comunidades indígenas, ya que se hace un reconocimiento legal de derechos indígenas, se construye normatividad que enmarca ese reconocimiento, pero se sigue siendo ciego y sordo de la dominación y el despojo de tierras, costumbres y modos de vida a través de proyectos asimilacionistas, sin consulta previa, por parte del Estado. La autora nos invita a preguntarnos si el multiculturalismo apunta a superar las desigualdades y bien si crea una categoría de indio permitido ${ }^{4}$ que disciplina y establece una forma de ser indígena, que neutraliza las exigencias de los pueblos, teatraliza la condición originaria, ancla a los pueblos indígenas en el pasado y los supone incapaces de conducir su propio destino. ${ }^{5}$

Además, en este primer bloque reflexiona sobre cómo hemos de nombrar estas formas de organización distintas a la estatal, de cuáles son las implicaciones denostativas y políticas, por ejemplo, de llamarlo como usos y costumbres y no como un sistema jurídico. Aborda también la urgencia de crear mecanismos reales y eficaces para configurar una relación intercultural, respetuosa y justa entre sistemas que permitan comprender la existencia de otras formas de organización.

Los capítulos II y III, El autogobierno Rarámuri. Algunos principios y estructuras generales y Entre el Ejido, la Sección y el Narco, respectivamente, exponen al autogobierno rarámuri, ya específicamente, respecto a sus procesos de transformación de sus autoridades, sus funciones, sus sistemas de elecciones, sus procedimientos de resolución de conflictos y sus mecanismos de sanción. En estos apartados hay una mirada atenta a una forma de existir y de organizarse con un talante distinto, diferente, como lo es la de las comunidades rarámuris, donde, por ejemplo, a diferencia del sistema positivo mexicano donde la escritura y el respaldo revestido de autoridad es muy importante, para el gobierno rarámuri lo importante está en el conocimiento colectivo que no aparece en algo escrito pero que sí se va reconstruyendo de a poco, entre todos, y a diario.

Hay algo muy singular en estos apartados, y es que es dónde más aparecen los testimonios resultado de las entrevistas realizadas a indígenas de la comunidad. Incluso los nombres de algunos de los subtemas devienen de esos testimonios como Aquí la gente habla y habla y todos participan, Fui a ver a quién pondrían y que me ponen a mí, Puede que no sea delito pero afecta a la comunidad. Es así como el análisis eclosiona de las voces de los mismos rarámuris, son ellos quienes desde su experiencia explican la manera en que participan, en

\footnotetext{
${ }^{3}$ Véase: BURGUETE CAL Y MAYOR, Aracely, “Autonomía: la emergencia de un paradigma en las luchas por la desconolonización en América Latina”, en La autonomía a debate. Autogobierno indígena y Estado plurinacional en América Latina, González, Burguete Cal y Mayor y Ortíz-T. (coords.), FLACSO, Ecuador, 2010.

4 Véase: HALE, Charles R., “¿Puede el multiculturalismo ser una amenaza? Gobernanza, derechos culturales y política de la identidad en Guatemala”, en Journal of Latin American Studies, núm. 34, 2004, pp. 485-524.

5 VALDIVIA RAMÍREZ, Fátima del Rocío, Ibidem., p. 18.
} 
que construyen, en que critican, en que deciden. De estas experiencias resulta trascendente resaltar que la comunidad rarámuri no tiene una conformación estandarizada ni escalonada; por lo tanto, comprenden que no siempre serán autoridad y pueden ser juzgados y sancionados, es decir, que todos forman parte del sostenimiento del orden.

La autora va trazando las relaciones asimétricas y de dominación histórica del derecho de la colonia y del derecho positivo vigente mexicano. Pone énfasis en la Reforma Agraria de 2009, que se consideró como una conquista campesina e indígena, que subsumió a la población rarámuri a intereses que nada tenían que ver con sus propias formas de gobierno; y evidencia cómo el discurso de los derechos humanos sin una interpretación intercultural puede obstaculizar la autonomía de los pueblos.

La Última parada: el Estado y su acceso a la justicia, nombre del último capítulo, trasluce que la inoperancia de nuestro sistema de justicia actual se agudiza cuando de regiones indígenas hablamos. Traduciéndose esto en una justicia hegemónica, pensada para unos cuantos o para un tipo específico de ciudadano, con un sistema de negociación respecto a los intérpretes traductores dónde quién decide si existe la necesidad de alguno para algún caso en concreto es el Ministerio Público o algún juzgado, y en donde la presencia de defensores o defensoras indígenas no existe o es casi nula.

Finalmente, Valdivia Ramírez concluye diciendo que el reconocimiento de las formas de autogobierno y derechos indígenas es un arma de doble filo porque, aunque es importante que la demanda indígena quede establecida de jure como protección a las comunidades, debemos tener cuidado con que ésta legalización no nos lleve a construir un indio permitido o simbólico que neutralice las luchas, negocíe en pro del desarrollo o que folclorice la interculturalidad. La autora destaca como un elemento clave de la resistencia y existencia de facto del autogobierno rarámuri, la actitud colaborativa y no combativa de conciliación y acción coordinada con otras autoridades, que pese a la existencia de las relaciones de desigualdad han permitido sostener un diálogo.

De manera concreta considera como principales retos superar el alcoholismo y la drogadicción; involucrar a los jóvenes en los procesos tradicionales; acabar con la idea del Estado monopólico de justicia para comenzar a pensar en una real pluralidad jurídica que respondería a la realidad de sociedades como la nuestra; operativizar a los intérpretes traductores, y; reformular las estructuras de jurisdicción y de concepción del derecho.

La obra de Valdivia Ramírez se circunscribe como un trabajo que recupera de las experiencias los horizontes de la lucha indígena, en específico, de la lucha por el autogobierno rarámuri. Su vigencia está en que evidencia que el problema no es la diversidad cultural en sí, sino que esta diversidad al no reconocerse como igual ante las instituciones del Estado y en el imaginario social, crea jerarquías que producen y reproducen relaciones de poder y de dominación. Discurrir acerca de la demanda indígena no sólo es urgente, sino que puede ser el inicio para comenzar a trazar un auténtico camino hacia la justicia de los pueblos indígenas. 
